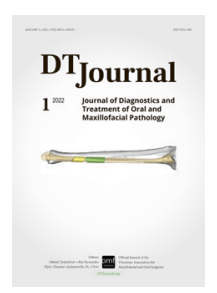

\title{
In Response to the Editorial "Meet the Founding Resident Ambassador: John M. Le, DDS, MD”
}

John M. Le

$I_{t}$ is an honor and privilege to accept the invitation to be the founding resident ambassador (Fig 1) for the Journal of Diagnostics and Treatment of Maxillofacial Pathology (JDTOMP), also known as DT Journal. ${ }^{1}$ I am excited to join an outstanding and diverse editorial board. In this new role, I aim to engage and recruit a diverse group of oral and maxillofacial surgery trainees from the United States and abroad to launch regular evidence-based discussions regarding the current therapies for maxillofacial pathology and advancements in oral and maxillofacial surgery. I hope to eventually create a board of resident advisors that will not only serve to promote DT Journal's presence on social media, but also as peer reviewers. The requirements for the future of the program and its incoming resident members will include the following:

1. Promotion of and sharing of issues published by the journal on social media outlets (i.e., Instagram, Facebook, LinkedIn) using \#dtjournalorg and \#jdtomp.

2. Creating and sharing posts on one's social media page as it relates to DT Journal using \#dtjournalorg and \#jdtomp.

3. Contributing to the journal by submitting an article of choice for peer review within two years of becoming a member.

4. Serve as a peer reviewer.

DDS MD; OMS Resident, University of Alabama at Birmingham, AL, USA. Resident Ambassador, Journal of Diagnostics and Treatment of Oral and Maxillofacial Pathology (JDTOMP).

E-mail:johnmtle@gmail.com

Please cite this article as: Le JM. In response to the editorial "Meet the founding resident ambassador: John M. Le, DDS, MD." J Diagn Treat Ora Maxillofac Pathol 2022;6(1):6.

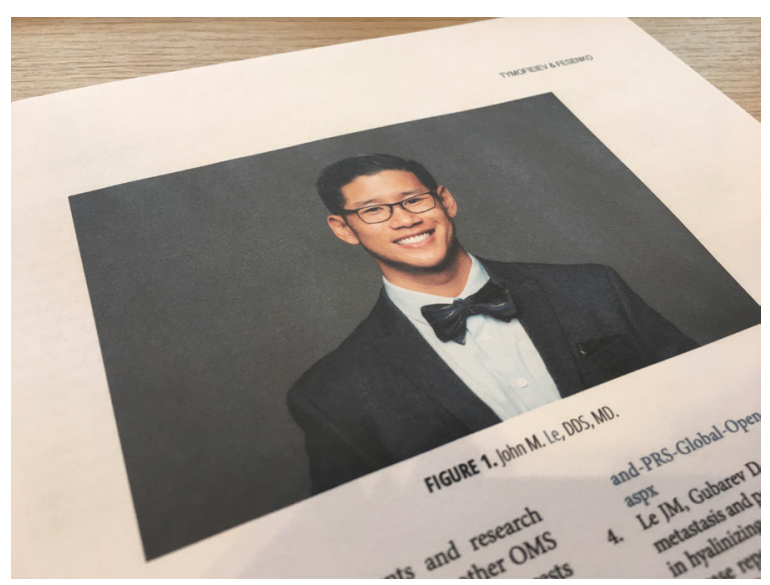

FIGURE 1. Printed PDF of the editorial.

All in all, as an inaugural program for the DT Journal, the resident member requirements will remain dynamic and subject to change in accordance with the Editorial Board's missions and goals.

\section{REFERENCE}

1. Tymofieiev OO, Fesenko II. Meet the founding resident ambassador: John M. Le, DDS, MD. J Diagn Treat Oral Maxillofac Pathol 2022;6(1):3-5.

https://doi.org/10.23999/j.dtomp.2022.1.2

Available online 29 January 2022

https://doi.org/10.23999/j.dtomp.2022.1.3

(C) 2022 OMF Publishing, LLC. This is an open access article under the CC BY license (http://creativecommons.org/licenses/by-nc/4.0/). 